\title{
Detection of Non-Formal and Informal Learning in learning communities supported by social networks in the context of a Cooperative MOOC
}

\author{
Juan Cruz-Benito \\ GRIAL Research Group \\ Department of Computers and Automatics \\ University of Salamanca \\ Salamanca, Spain \\ juancb@usal.es
}

\author{
Oriol Borrás-Gené \\ Gabinete de Tele-Educación (GATE) \\ Technical University of Madrid \\ Madrid, Spain \\ oriol.borras@upm.es
}

\author{
Francisco J. García-Peñalvo \\ GRIAL Research Group \\ Department of Computers and \\ Automatics \\ University of Salamanca \\ Salamanca, Spain \\ fgarcia@usal.es
}

\author{
Ángel Fidalgo Blanco \\ Technical University of Madrid \\ Madrid, Spain \\ afidalgo@dmami.upm.es
}

\author{
Roberto Therón \\ Department of Computers and \\ Automatics \\ University of Salamanca \\ Salamanca, Spain \\ theron@usal.es
}

\begin{abstract}
This paper retrieves information and makes basic analysis about the participation of users involved in Cooperative MOOCs in Learning Communities supported by hypermedia environments like the social networks. In order to perform this study, the interaction of a set of users enrolled in a course within the iMOOC platform has been analyzed, in which MOOC courses are implemented based on concepts like connectivism, collaborative learning, gamification or adaptivity. Specifically, this study deals with obtaining information about the discussions that take place in learning communities created using social networks like Google+ and Twitter in parallel of the activities performed inside the iMOOC platform. Through this information, this paper tries to distinguish the types of learning that occurs in those discussions (non-formal and informal learning), estimating also how users interact with tagged content in social networks, and how that allows students -users- to continue or create conversations that help to expand or strengthen the content they treated during the MOOC course.
\end{abstract}

Keywords-MOOC, iMOOC, Twitter, Google+, Collaborative Learning, Informal Learning, Non-formal Learning, eLearning

\section{INTRODUCTION}

The emergence of the Internet and the concept of eLearning have radically altered the way we, the humans, learn and interact with the knowledge [1-4]. Specifically, this change has suffered an outstanding acceleration process with the emergence of new theories, methodologies, tools and systems designed and implemented to leverage more and better the online medium to facilitate knowledge acquisition and learning by the concerned learners, without regardless of age, gender or other personal conditions [5]. Currently, MOOC (Massive Open Online Courses) are specially in fashion [6]. These learning environments make available virtual classes as a open containers of knowledge to many users (often thousands) [7,
8], providing learning resources for all the users enrolled in the course as well as methods and systems to reinforce the knowledge acquisition from different views [9].

Moreover, besides the revolution that has brought the eLearning within the scope of learning, it should be noted that learning is not currently conceived from classic formal point of view. According to the literature [10-13], currently, we can distinguish three types of learning:

- Formal learning is "which occurs in organized and structured environments (i.e. schools or work environment) and it is explicitly designed as learning in terms of objectives, time and resources. Typically it leads to validation and certification of the knowledge gained".

- Non-formal learning is "which is embedded in planned learning without being explicitly raised as learning activities. However, occasionally non-formal learning can be validated and lead to certification".

- Informal learning is "the learning that results from daily activities related to work, family or leisure. It is a not organized learning, unstructured in terms of objectives, timing or in the support typical of structures related to learning".

In parallel to the environments purely designed for the eLearning development, for several years intermingled in these tasks other platforms and horizontal systems that link its use to concepts such as Informal Learning. For example, the usage of social networks in learning, where these social networks support many times true learning communities [14], where conversations take place, content is shared in an open way, relationships are established among users (in a horizontal way 
in many cases), interactions between people and digital entities occur, etc. That is, social networks are a real Petri plate where users built digital societies through the development of communication structures, consumption patterns (in this case information) and user networks in a comprehensive way. It is in these social networks, in these digital societies, where various aspects previously commented can be merged: the eLearning in a non-formal or informal context, and also in a formal way [15]. Such as different authors discuss [16-18], informal conversations and the contents present in social networks are currently one of the most successful ways to acquire extra knowledge and improve the learning experience in online courses. Moreover, certain conversations and interactions that occur in social networks can be a result of the realization by social network users of any type of learning activity (online or offline activities) [19]. Regarding that, it is possible to cite the theory of Connectivism [20,21], which enacts that the learning process is enriched by connecting students, teachers and online resources. Also it can be added that social networks are a perfect way to improve this connection [22], so they can favor the outcrop of real connected communities of learning and practice [23].

This paper is about exactly on the latter issues, it presents a study of the informal discussions and interactions of a MOOC course students with the MOOC contents in both non-formally and informally ways [24]. The MOOC course used for the study is housed in a MOOC platform developed by the Technical University of Madrid, the University of Zaragoza and the University of Salamanca, and it is called iMOOC. This MOOC platform is based on non-formal and informal learning and has features like adaptivity [25], gamificaction [26], or collaborative learning [27] among others. Section 2 (Materials and Methods) provides a more complete description on iMOOC. Thus, the main objective of the paper is to study the conversations and user interactions with the contents of the MOOC, or related to it, on social networks like Google+ or Twitter. This study of conversations would be used to detect what type of learning occurs (non-formal, informal, etc.) and how users utilize labeling resources in such networks (i.e. hashtags) [28] to support the learning. This objective, and other contents and related concepts are discussed in the following sections: Materials and Methods, Results, Discussion and Conclusions.

\section{MATERIALS AND METHODS}

\section{A. Materials}

\section{1) $i M O O C$}

The iMOOC platform or intelligent-MOOC platform (goo.gl/zIUOBo) in which, among other actions, it includes the creation of MOOC courses based on adaptive and informal learning [13, 29-32]. To achieve this objective, the project uses the eLearning platform Moodle (http://goo.gl/Le9y9j), specifically the version 2.6.5, taking advantage of its versatility.

This adapted learning is possible through the use of different tools offered by the platform, such as conditionals, groupings that let to create groups, associating to them different course resources and leading to different educational pathways, depending on the type of user profile, the chosen subjects, the students' progress within the course and their level of knowledge.

\section{2) iMOOC Course "Social networks and learning"}

The January 12, 2015 a first demo of the iMOOC platform was launched with the course "Social networks and learning", a special version of the course "Application of social networking to teaching" presented earlier at the MiriadaX platform (http://goo.gl/bm5Bah). This course uses the cooperative model of Fidalgo et al. $[33,34]$ that collects characteristics of both the two more standardized types of MOOC such as the xMOOC and the cMOOC. The xMOOC has main features like its behavioral approach and its similarity to the traditional online courses and the cMOOC is focused more on the connectivist approach [35] based on social networks. To explain this cooperative model, the course can be divided into a series of layers, starting with the "technological" layer that includes the MOOC platform that houses the course and the social platforms where interactions occur among participants that lead to content generation. This layer is followed by the "training strategy" layer, associated with instructional design of the course itself. Finally, it can be highlighted the "cooperative" layer that represents the connectivist part of the course that collects the results and contents generated through the cooperation between the teaching staff and the participants of the course, integrating these contents in the course. It is needed to add to this defined cooperative model a fourth layer to explain the gcMOOC model ( $g$ for gamification, $c$ for cooperation) in which the course is based on. This fourth layer is called the gamification [36] layer and interacts with the other layers, promoting the motivation of participants in the course [36].

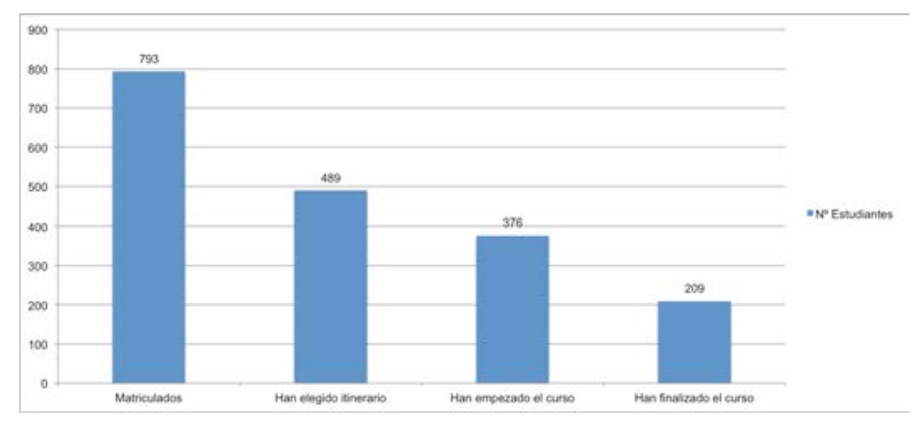

Figure 1. Distribution of students regarding enrollment, choice of itinerary to study (there were specializations within the content regarding the itinerary), initiation and completion of the MOOC course.

Regarding to the contents of the course, they are intended to introduce students in the usage of the social web for a month and its opportunities within the field of education, more specifically in the generation of virtual learning communities. On the other hand, it delves into the use of the most common horizontal social networks such as Facebook, Twitter and Google+, helping the students to develop the necessary digital skills to use them in learning, while it provides a set of guidelines for its use in the classroom. Finally, the course provides an overview of another 13 other social networks that are also suitable for this teaching purposes, as well as tools for its optimal management. As general information about the users' engagement to the course and the metrics on completion. Figure 1 and Figure 2 show a summary about these topics. 


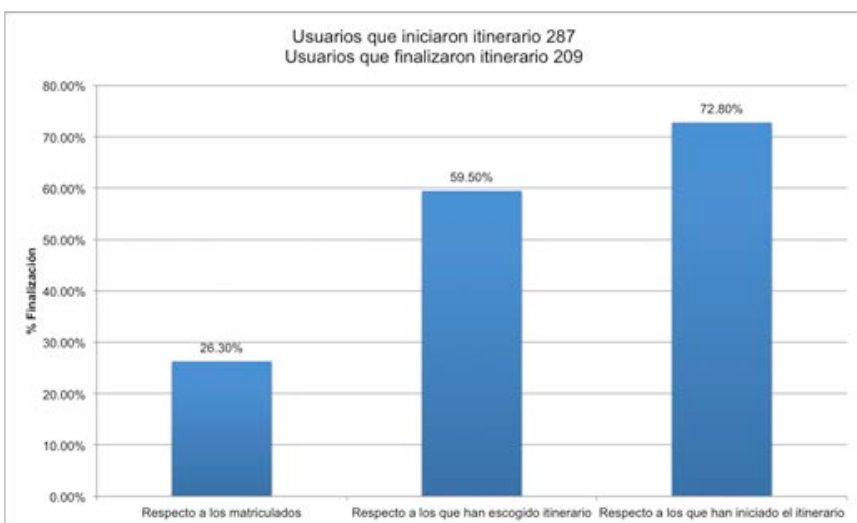

Figure 2. Chart about the students' initiation and completion of the MOOC course (excluding the students that participated last year and just wanted to access content updated).

3) The social networks used: Google+ y Twitter

Being a course that deals with topics about "social networking in learning", and given the connectivist approach of the MOOC, the social networks have played an important role in the learning process associated with the course. These networks have been used under two different perspectives: one is the use of social networks such as test environments, as well as case studies to get a practical understanding of the concepts shown theoretically in the course; while the other perspective is its use as a platform to continue and extend the learning process within the iMOOC course from both a non-formal and informal perspectives. To extend the learning process teachers suggested conversations conveniently labeled (using hashtags) to open new ways of discussion and knowledge acquisition from a non-formal view and trying to encourage the outcrop of conversations and informal learning among the students enrolled in the MOOC in a different environment, as well as with other social networks users involving them in the conversation without being enrolled in the course [37] as shown in the Figure 3.

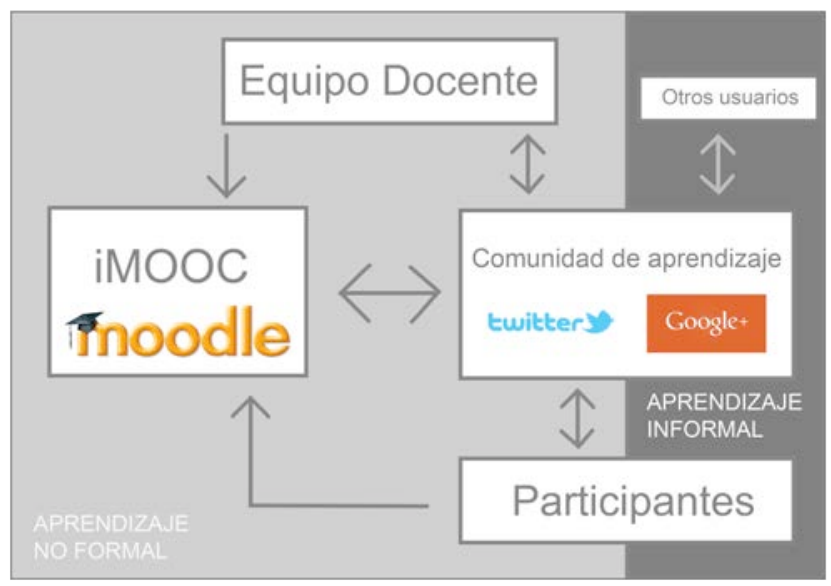

Figure 3. Scheme of the interaction between, users, iMOOC platform and social networks, segmented by type learning that occurs at each stage.

For this task, this MOOC has used social networks Google+ and Twitter. In Google+ this course is associated, since its inception in MiriadaX, to a community of more than 5,000 users (http://goo.gl/eevdjY) where resources are shared and the users contribute to the learning associated with each edition of the course. Regarding Twitter, it has been used as an alternative social network to raise discussions and conversations between users, due to the current popularity and the facilities it offers regarding to the conversation tagging, and for tracking and retrieving information from these discussions [38, 39]. In the following sections (Methods, Results, Discussion and conclusions) the paper outlines the process that has been carried out to track, recover and explore the data to achieve the objectives both in the case of Twitter and Google+.

\section{B. Methods}

To obtain information about the interaction of iMOOC users with course contents in social networks, it has been necessary the establishment of the appropriate retrieval information mechanisms about the relationships among iMOOC users' profiles and the different social networks they use. Also, it is required to retrieve the information they share and label in order to perform the analysis that are presented as study objectives.

The main methods used are [40]:

- To avoid a manual recovery of data for each user, Moodle (on which the iMOOC is built) web services (REST APIs http://goo.gl/ItdjPP) have been used. So it is possible the access to the records of users and their profiles, enabling the filtering of those who have registered their profiles on social networks. This tracking was proposed by the MOOC teachers to help evaluation of the students

- To extract information from Twitter, it has been combined the automatic recovery of tweets (through its REST API http://goo.gl/GPqCiJ) with the manual recovery of some specific metrics. For the extraction of information from the social network Google+, due to the lack of APIs to retrieve information from user communities (http://goo.gl/SSCxb0), it has been necessary to develop a tool called GILCA (Google Analytics Informal learning Communities) which collects data from Google+ communities through the email notifications sent by the network (which includes information on publications, comments, hashtags, etc.).

- To understand how users manage the labeling functions in social networks, authors conducted a questionnaire which ask to students about basic questions about the use of hashtags in social networks and activities related to the course.

To analyze the data, authors used tools like spreadsheets.

\section{RESULTS}

To obtain the results about the use of social networks, authors filtered users that had indicated their Google+ or Twitter profile on their iMOOC profile, being able by this way to recover what they had posted on social networks following the "official" hashtags proposed for the course (Figure 4, Table 1). Once checked that, authors proceeded to assess the number of publications they had done and what proportion of users that 
published on Google+ or Twitter and finally approved or not the course. This evaluation resulted:

- Students enrolled in the course have made a total of 263 posts in the community of Google+ (also counting comments to other publications from other students).

- Students enrolled in the course have posted a total of 131 tweets following both official and non-official hashtags on Twitter.

- 191 students published any comment or content on Google+, 57 of them approved the course $(29.84 \%)$.
- 76 users posted a tweet on Twitter, 42 of them approved the course $(55.26 \%)$.

- 191 users indicated their Google+ profile on iMOOC profile, 83 of them approved the course $(43.5 \%)$.

- 265 users indicated their Twitter profile in their iMOOC profile, 105 of them approved the course $(39.62 \%)$.

In addition to the recovery of data from social networks, authors made some initial research about the time distribution in the use of non-formal and informal hashtags (Figure 5, Figure 6).

Table 1. Distribution of interactions on Google+ and Twitter by type of content and learning.

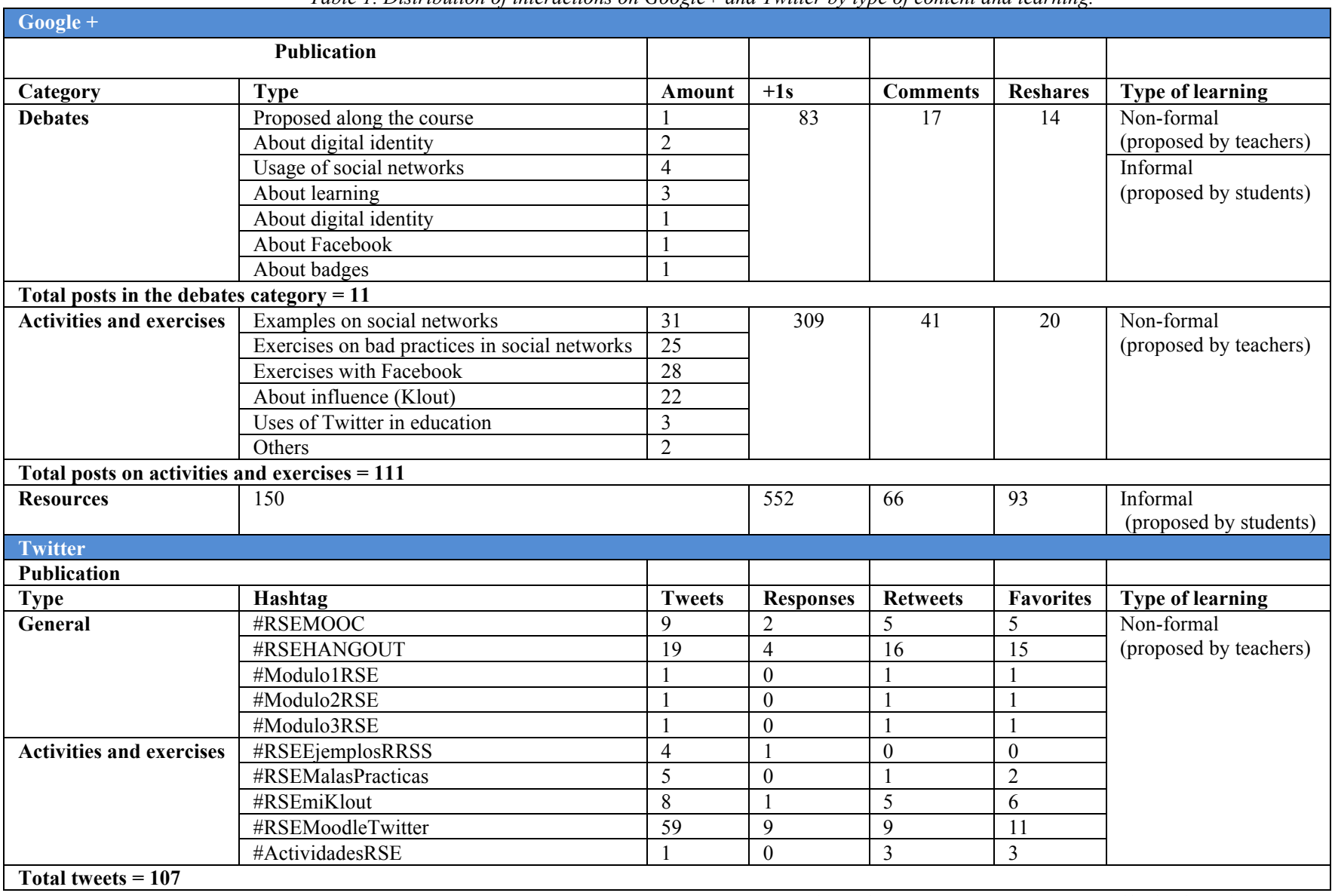

\section{DiSCUSSION AND CONCLUSIONS}

Both hashtags on Twitter or Google+, and categories in the Google+ network provide an opportunity for collaborative MOOCs and their characteristics related to non-formal and informal learning, allowing to classify and collect the contents generated in the communities related to the course, and feed back the MOOC based on this non-formal and informal content. The main drawback when recovering this labelled knowledge, as can be seen from the results, is the lack of digital skills, practice, and awareness on the part of the participants in this type of learning communities, due to usually the result of talks are publications with no labeling, or in many cases finding that such hashtags do not match the proposed in the course or are misspelled, thus hindering their recovery and forcing cleaning tasks and manual selection of publications.

On the other hand, it can be clearly observed how the Google+ network has created a differentiated space for the course community by using the Communities tool; thanks to this differentiation can be easily recovered the conversations even when new hashtags appear (not defined in the course) or they are not tagged. By contrast, in Twitter seems essential using in the tweets related to the course one of a hashtag previously defined (non-formal) to detect, by this way, the conversations. If not, some information can be lost due to the recovery of "informal" hashtags is very difficult. So, it is 
possible to say that Twitter hinders the recovery of informal conversations unlike Google + .

Notably, following the results, some remarkable informal conversations in the community initiated by the students, which is promoted to provide new content to other students. This can be distinguished as a result of informal activity initiated or even infused by the mechanics of the MOOC course. It is possible to observe, for example, how informal activities are reflected as publications of students, and how it leads to a deliberate interaction of other students through indicators of approval such as " $+1 \mathrm{~s}$ " with more than 300 throughout the course associated with those activities or informal comments associated.

On comparing the results in MOOC grades with performance on social networks, in many cases, users that point out their social network and post messages are more interested in completing the course, due to there are significant results that indicate a relationship between activity in both directions, although it is true that this relationship is more pronounced in the social network Twitter than in Google+. Because of these results, as a conclusion it can be asserted that it is possible to retrieve and classify non-formal and informal learning in environments like social networks. This retrieval and classification can shed light on the learning complex processes (in metrics like distribution in time, indicators of interest, possibility of increasing the segmentation adaptivity of MOOC platform through the observed data in Figures 5 and 6 , etc.) that occur in massive digital societies like the social networks presented [41].

Regarding to other possibilities offered by this type of analysis, making further analysis at user level, probably it can be possible to classify types of users based on their activity on social networks and MOOC, thus allowing to find influencers (influential users), students who behave as spectators, users that really have no interest in completing a course but learning part of the contents, etc.

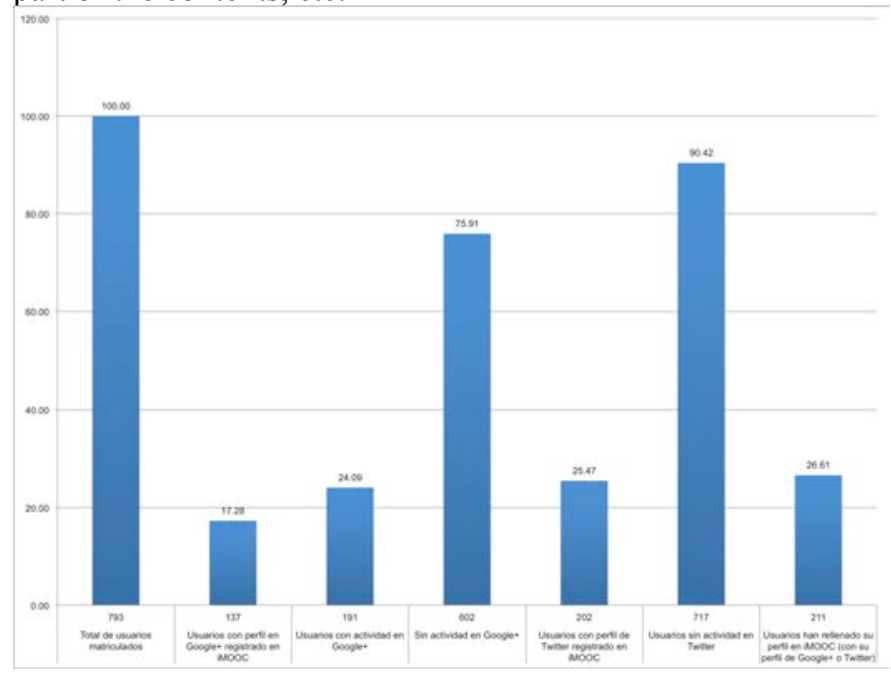

Figure 4. Distribution of iMOOC users regarding their use of social networks

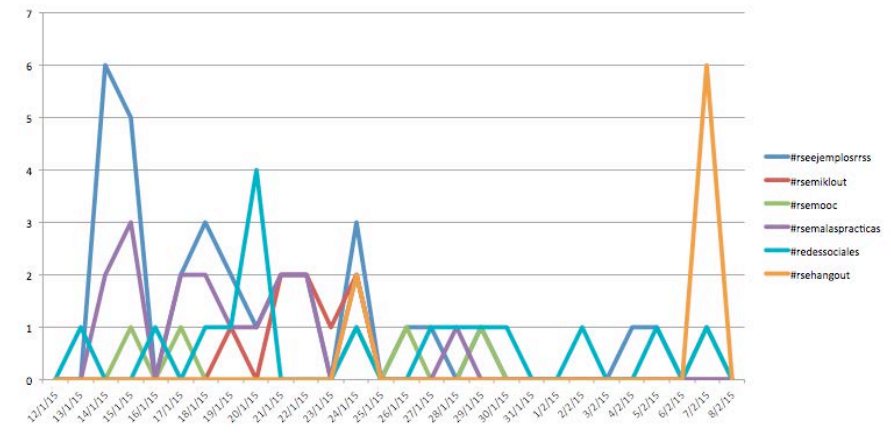

Figure 5. Evolution of non-formal hashtags throughout the course.

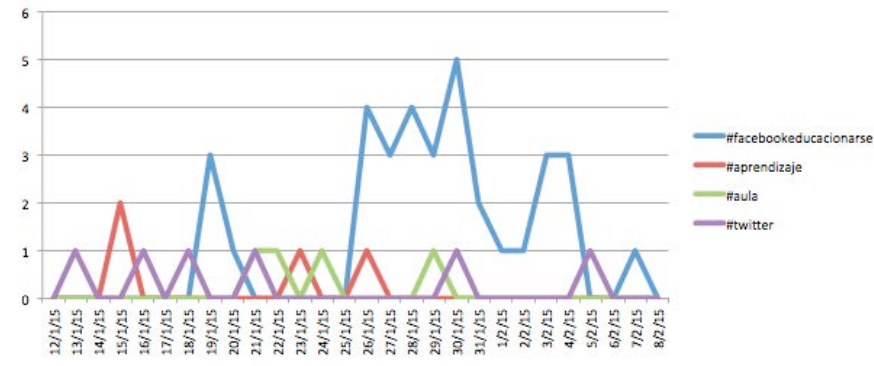

Figura 6. Evolution of informal hashtags throughout the course

\section{ACKNOWLEDGEMENTS}

The authors would like to thank Research Groups GRIAL and LITI for their collaboration in this research. Similarly, the authors would like to thank the Technical University of Madrid for their support and funding through the project "Diseño $y$ desarrollo de MOOC universitarios ("Design and development of academic MOOCs")" (Ref. PT1415-05000) and to Vice President for Academic Policies at the University of Salamanca for funding the Teaching Innovation project ID2014 / 0281 that has enabled the authors to develop the software architecture described in this paper. Also the author Juan Cruz-Benito would like to thank the European Social Fund and the Consejería de Educación of the Junta de Castilla y León (Spain) for funding his predoctoral fellow contract.

\section{REFERENCES}

F. J. García-Peñalvo and A. M. Seoane Pardo, "Una revisión actualizada del concepto de eLearning. Décimo Aniversario," Education in the Knowledge Society (EKS), vol. 16, pp. 119-144, 2015.

B. A. Collis, Tele-learning in a digital world: The future of distance learning: International Thomson Computer Press, 1996.

M. J. Rosenberg, E-learning: Strategies for Delivering Knowledge in the Digital. New York, NY, USA: McGraw-Hill, 2001.

F. J. García-Peñalvo, Advances in E-Learning: Experiences and Methodologies. Hershey, PA, USA: Information Science Reference (formerly Idea Group Reference), 2008.

J.-M. Dodero, F.-J. García-Peñalvo, C. González, P. Moreno-Ger, M.-A. Redondo, A. Sarasa, et al., "Development of E-Learning Solutions: Different Approaches, a Common Mission," IEEE Revista Iberoamericana de Tecnologías del Aprendizaje (IEEE RITA), vol. 9, pp. 72-80, 2014.

F. J. García-Peñalvo, Á. Fidalgo Blanco, and M. L. Sein-Echaluce Lacleta. (2014, 6/1/2014). Tendencias en los MOOCs. Available: http://gredos.usal.es/jspui/handle/10366/125093 F. J. García-Peñalvo, C. García de Figuerola, and J. A. MerloVega, "Open knowledge: Challenges and facts," Online Information Review, vol. 34, pp. 520-539, 2010. 
[8] M. S. Ramírez Montoya, "Acceso abierto y su repercusión en la Sociedad del Conocimiento: Reflexiones de casos prácticos en Latinoamérica," Education in the Knowledge Society (EKS), vol. 16, pp. 103-118, 2015.

[9] C. Castaño Garrido, I. Maiz Olazabalaga, and U. Garay Ruiz, "Diseño, motivación y rendimiento en un curso MOOC cooperativo," Comunicar, vol. 44, pp. 19-26, 2015.

[10] V. J. Marsick and K. E. Watkins, "Informal and Incidental Learning," New Directions for Adult and Continuing Education, vol. 2001, pp. 25-34, 2001

[11] F. J. García-Peñalvo, R. Colomo-Palacios, and M. D. Lytras, "Informal learning in work environments: training with the Social Web in the workplace," Behaviour \& Information Technology, vol. 31, pp. 753-755, 2012.

[12] H. Eshach, "Bridging in-school and out-of-school learning: Formal, non-formal, and informal education," Journal of science education and technology, vol. 16, pp. 171-190, 2007.

[13] Á. Fidalgo Blanco, M. L. Sein-Echaluce Lacleta, and F. J. GarcíaPeñalvo, "Methodological Approach and Technological Framework to break the current limitations of MOOC model," Journal of Universal Computer Science, vol. 21, pp. 712-734, 2015.

[14] C. Alario-Hoyos, M. Pérez-Sanagustín, C. Delgado-Kloos, H. Parada G, M. Muñoz-Organero, and A. Rodríguez-de-las-Heras, "Analysing the Impact of Built-In and External Social Tools in a MOOC on Educational Technologies," in Scaling up Learning for Sustained Impact. vol. 8095, D. Hernández-Leo, T. Ley, R. Klamma, and A. Harrer, Eds., ed: Springer Berlin Heidelberg, 2013, pp. 5-18.

[15] J. Sanchez, C. González, S. Alayón, and P. Gonzalez, "Using social networks at university: The case of school of computer science," in Global Engineering Education Conference (EDUCON), 2013 IEEE, ed USA: IEEE, 2013, pp. 492-496.

[16] J. Mackness, S. Mak, and R. Williams, "The ideals and reality of participating in a MOOC," in 7th International Conference on Networked Learning, ed, 2010, pp. 266-275.

[17] A. McAuley, B. Stewart, G. Siemens, and D. Cormier. (2010). The MOOC model for digital practice. Available: http://www.elearnspace.org/Articles/MOOC Final.pdf

[18] F. J. García-Peñalvo, M. Johnson, G. R. Alves, M. Minović, and M. Á. Conde-González, "Informal learning recognition through a cloud ecosystem," Future Generation Computer Systems, vol. 32, pp. 282-294, 2014

[19] K. Silius, T. Miilumaki, J. Huhtamaki, T. Tebest, J. Merilainen, and S. Pohjolainen, "Students' motivations for social media enhanced studying and learning," Knowledge Management \& ELearning: An International Journal (KM\&EL), vol. 2, pp. 51-67, 2010.

[20] G. Siemens, "Connectivism: A learning theory for the digital age," International journal of instructional technology and distance learning, vol. 2, pp. 3-10, 2005.

[21] M. Zapata-Ros, "Teorías y modelos sobre el aprendizaje en entornos conectados y ubicuos. Bases para un nuevo modelo teórico a partir de una visión crítica del "conectivismo"," Education in the Knowledge Society (EKS), vol. 16, pp. 69-102, 2015.

[22] C. Evans, "Twitter for teaching: Can social media be used to enhance the process of learning?," British Journal of Educational Technology, vol. 45, pp. 902-915, 2014.

[23] E. C. Wenger and W. M. Snyder, "Communities of practice: The organizational frontier," Harvard business review, vol. 78, pp. 139$146,2000$.

[24] J. West, "Recognition of non-formal and informal learning: the Case Against. Study prepared for the meeting of the OECD Group of Experts," Vienna. 2007.

[25] A. J. Berlanga and F. J. García-Peñalvo, "Learning Design in Adaptive Educational Hypermedia Systems," Journal of Universal Computer Science, vol. 14, pp. 3627-3647, 2008.

[26] F. J. Sánchez i Peris, "Gamificación," Education in the Knowledge Society, vol. 16, pp. 13-15, 2015

[27] Á. Fidalgo-Blanco, M. L. Sein-Echaluce, F. J. García-Peñalvo, and M. Á. Conde, "Using Learning Analytics to improve teamwork assessment," Computers in Human Behavior, vol. 47, pp. 149-156, 2015.

[28] F. J. García-Peñalvo, J. Cruz-Benito, O. Borrás-Gené, and Á Fidalgo Blanco, "Evolution of the Conversation and Knowledge Acquisition in Social Networks related to a MOOC Course.," in Learning and Collaboration Technologies. Second International Conference, LCT 2015, Held as Part of HCI International 2015 Los Angeles, CA, USA, August 2-7, 2015, Proceedings, P. Zaphiris and I. Ioannou, Eds., ed Switzerland: Springer International Publishing, 2015, pp. 470-481.

[29] Á. Fidalgo Blanco, F. J. García-Peñalvo, and M. L. Sein-Echaluce Lacleta, "A methodology proposal for developing adaptive cMOOC," in Proceedings of the First International Conference on Technological Ecosystem for Enhancing Multiculturality, F. J. García-Peñalvo, Ed., ed New York, USA: ACM, 2013, pp. 553558 .

[30] Á. Fidalgo Blanco, M. L. Sein-Echaluce Lacleta, and F. J. GarcíaPeñalvo, "Methodological Approach and technological Framework to break the current limitations of MOOC model," Journal of Universal Computer Science, vol. In press, 2015.

[31] N. Sonwalkar, "The first adaptive MOOC: A case study on pedagogy framework and scalable cloud Architecture-Part I," MOOCs Forum, vol. 1, pp. 22-29, 2013.

[32] J. Daniel, E. V. Cano, and M. Gisbert, "The Future of MOOCs: Adaptive Learning or Business Model?," RUSC. Universities and Knowledge Society Journal, vol. 12, pp. 64-73, 2015.

[33] Á. Fidalgo Blanco, M. L. Sein-Echaluce Lacleta, and F. J. GarcíaPeñalvo, "MOOC cooperativo. Una integración entre cMOOC y xMOOC. Cooperative MOOC. An integration between cMOOC and xMOOC," in II Congreso Internacional sobre Aprendizaje, Innovación y Competitividad, CINAIC 2013, Á. F. Blanco and M. L. S.-E. Lacleta, Eds., ed Madrid: Fundación General de la Universidad Politécnica de Madrid, 2013, pp. 481-486.

[34] Á. Fidalgo-Blanco, M. L. Sein-Echaluce, and F. J. García-Peñalvo, "Epistemological and ontological spirals: From individual experience in educational innovation to the organisational knowledge in the university sector," Program: Electronic library and information systems, vol. 49, pp. 266-288, 2015.

[35] Á. Fidalgo Blanco, M. L. Sein-Echaluce Lacleta, O. Borrás Gené, and F. J. García Peñalvo, "Educación en abierto: Integración de un MOOC con una asignatura académica," Education in the Knowledge Society (EKS), vol. 15, pp. 233-255, 2014.

[36] O. Borrás Gené, M. Martínez Núñez, and Á. Fidalgo Blanco, "Gamification in MOOC: challenges, opportunities and proposals for advancing MOOC model," in Proceedings of the Second International Conference on Technological Ecosystems for Enhancing Multiculturality, F. J. García-Peñalvo, Ed., ed New York, USA: ACM, 2014, pp. 215-220.

[37] Á. Fidalgo-Blanco, M. L. Sein-Echaluce, F. J. García-Peñalvo, and J. Esteban Escaño, "Improving the MOOC learning outcomes throughout informal learning activities," in Proceedings of the Second International Conference on Technological Ecosystems for Enhancing Multiculturality, F. J. García-Peñalvo, Ed., ed New York, USA: ACM, 2014, pp. 611-617.

[38] J. Huang, K. M. Thornton, and E. N. Efthimiadis, "Conversational tagging in twitter," in Proceedings of the 21st ACM conference on Hypertext and hypermedia, 2010, pp. 173-178.

[39] M. Efron, "Hashtag retrieval in a microblogging environment," in Proceedings of the 33rd international ACM SIGIR conference on Research and development in information retrieval, 2010, pp. 787788 .

[40] J. Cruz-Benito, O. Borrás-Gené, F. J. García-Peñalvo, Á. Fidalgo Blanco, and R. Therón, "Extending MOOC ecosystems using web services and software architectures," presented at the Interacción 2015. XV International Conference on HCI, Villanova I la Geltrú, Spain., 2015.

[41] J. Cruz-Benito, O. Borrás-Gené, F. J. García-Peñalvo, Á. Fidalgo Blanco, and R. Therón, "Detección de aprendizaje no formal e informal en Comunidades de Aprendizaje soportadas por Redes Sociales en el contexto de un MOOC Cooperativo," in Actas del XVII Simposio Internacional de Informática Educativa (SIIE'15) (Setúbal, Portugal. 25-27 November 2015), M. d. R. r. Rodrigues, 
